\title{
Mechanical properties of high alloyed cast and rolled CrMnNi TRIP steels with varying $\mathrm{Ni}$ contents
}

\author{
A. Jahn ${ }^{\text {al }}$, A. Kovalev ${ }^{1}$, A. Weiß ${ }^{1}$, P.R. Scheller ${ }^{1}$, S. Wolf ${ }^{2}$, L. Krüger ${ }^{2}$, S. Martin ${ }^{3}$, U. Martin ${ }^{3}$ \\ ${ }^{1}$ Institute of Iron and Steel Technology, TU Bergakademie Freiberg, D-09596 Freiberg/Saxony, Germany \\ ${ }^{2}$ Institute of Materials Testing, TU Bergakademie Freiberg, D-09596 Freiberg/Saxony, Germany \\ ${ }^{3}$ Institute of Materials Science, TU Bergakademie Freiberg, D-09596 Freiberg/Saxony, Germany
}

\begin{abstract}
High alloyed metastable austenitic or austenitic-martensitic steels show a strain induced formation of martensite during mechanical loading. These kinds of steels are well known as material for rolled products. Based on the System Fe-Cr-Mn-Ni a new generation of cast steels with TRIP effect will be discussed. The investigations show how the mechanical properties and the fraction of the formed martensite are influenced by varying $\mathrm{Ni}$ contents. The mechanical properties in the cast state of the material are quite similar to those in the rolled state. This is valid for tensile as well as compression loading. Under certain conditions, an isothermal formation of martensite was observed in some of the steels. The experimental results are based on tensile and compression tests. The specimens were analysed by optical microscopy, electron backscatter diffraction (EBSD), dilatometer tests and a special method for the detection of the ferromagnetic phase contents, the magnetic balance.
\end{abstract}

\section{Introduction}

It is well known that austenitic chromium-nickel or chromium-manganese-nickel steels with low stacking fault energy show a stress and strain induced formation of martensite during mechanical loading. The transformation induced plasticity (TRIP) effect occurs in metastable austenitic or austenitic-martensitic steels for wrought and also cast alloys [1]. The strain induced formation of martensite is controlled as well by its chemical composition as by stresses [2]. These stresses are higher than the yield stress of the initial microstructure and they activate shear processes which are accompanied by deformations. For each type of strain induced martensite formation a triggering stress exists which is controlled by the temperature and the chemical composition of the steel. This can be obtained from suitable experiments [3-5]. Generally three mechanisms of the martensite formation, the $\gamma \rightarrow \varepsilon, \varepsilon \rightarrow \alpha^{\prime}$ and $\gamma \rightarrow \alpha^{\prime}$ transformation, are discussed in Cr-Ni steels. During the $\gamma \rightarrow \varepsilon$ transformation the $\varepsilon$ phase is registered as thin straight-line plates in the microstructure of the austenite [6]. The $\gamma \rightarrow \varepsilon$ and $\varepsilon \rightarrow \alpha^{\prime}$ transformation can proceed simultaneously. The result is the $\gamma \rightarrow \varepsilon \rightarrow \alpha^{\prime}$ sequence [3-4]. During this process the $\varepsilon$ martensite is an instable intermediate phase and can usually not be detected. In $\mathrm{Cr}-\mathrm{Mn}-\mathrm{Ni}$ steels the $\varepsilon$ martensite is an intensively discussed subject. It is open either the $\varepsilon$ martensite is a unique phase or a pseudophase caused by the concentration of stacking faults in the direction of load. The reasons for these plastic deformations are the commonly observed phenomena shearing strain, twinning and different slip processes in the initial phase. Thus, some of these mechanisms are linked to special movements of dislocations. The strain induced formation of martensite generates the TRIP effect. It is well known that the microstructure of steels with low stacking fault energy of the austenite shows a high density of different defects, particularly in the case of the deformed austenite. Consequently the distinction of $\varepsilon$ martensite plates from stacking faults, glide and shear bands and twins in the austenite is a problem which can not be solved by optical microscopy.

In the present work $\mathrm{Cr}-\mathrm{Mn}-\mathrm{Ni}$ steels with varying $\mathrm{Ni}$ contents have been investigated in order to understand how the mechanical properties and the microstructure in the rolled as well as in the cast state are influenced by nickel. Naturally the grain size in the cast state is much higher than in the rolled one. It was surprising that the mechanical properties in the cast state of the material are quite similar to those in the rolled state.

\footnotetext{
a e-mail: Andreas.Jahn@iest.tu-freiberg.de
} 


\section{Experimental}

The austenitic and austenitic-martensitic steels were melted in a vacuum induction furnace. The steels were cast by using the rising casting technique, into a copper mould, placed in the furnace chamber. As result two ingots out of each melt were obtained. One of them was rolled into beams with a diameter of $12 \mathrm{~mm}$. The specimens were worked out of the cast ingot as well as of the beams. After the final machining, each sample was heat treated at $1050{ }^{\circ} \mathrm{C}$ for 30 minutes under vacuum followed by subsequent quenching. The chemical composition of the steels is given in Table $\mathbf{1}$ seen below.

Table 1. Chemical composition of the investigated steels

\begin{tabular}{|c|c|c|c|c|c|c|c|c|}
\hline & $\mathrm{C}$ & $\mathrm{N}$ & $\mathrm{Si}$ & $\mathrm{Mn}$ & $\mathrm{Cr}$ & $\mathrm{Mo}$ & $\mathrm{Ni}$ & $\mathrm{Fe}$ \\
\hline $16-7-3$ & 0,028 & 0,009 & 1,02 & 7,0 & 16,4 & 0,05 & 3,09 & bal. \\
\hline $16-7-6$ & 0,031 & 0,011 & 1,12 & 7,1 & 16,2 & 0,06 & 5,90 & bal. \\
\hline $16-7-9$ & 0,031 & 0,013 & 1,09 & 6,9 & 16,4 & 0,07 & 8,97 & bal. \\
\hline
\end{tabular}

After the tensile and compression tests the specimens were analysed by optical microscopy, electron backscatter diffraction (EBSD), dilatometer tests and the magnetic balance. The magnetic balance is a method for the detection of the ferromagnetic phase contents. This method is based on the force, affected on a ferromagnetic matter in a magnetic field. The force effects a displacement of a scale arm. With a magnetic field on the other scale arm, directed in the opposite direction, this displacement can be compensated. The force is proportional to the measured current that creates the magnetic field. With a calibration specimen, with known ferromagnetic phase fraction, the unknown ferromagnetic phase content can be detected by using this calibration correlation.

\section{Results and Discussion}

\section{Strain induced $\alpha^{\prime}$ martensite formation Tensile and compression tests}

Fig. 1 and 2 shows some selected technical tensile stress strain and technical compressive stress strain curves of the investigated steels at room temperature, respectively.
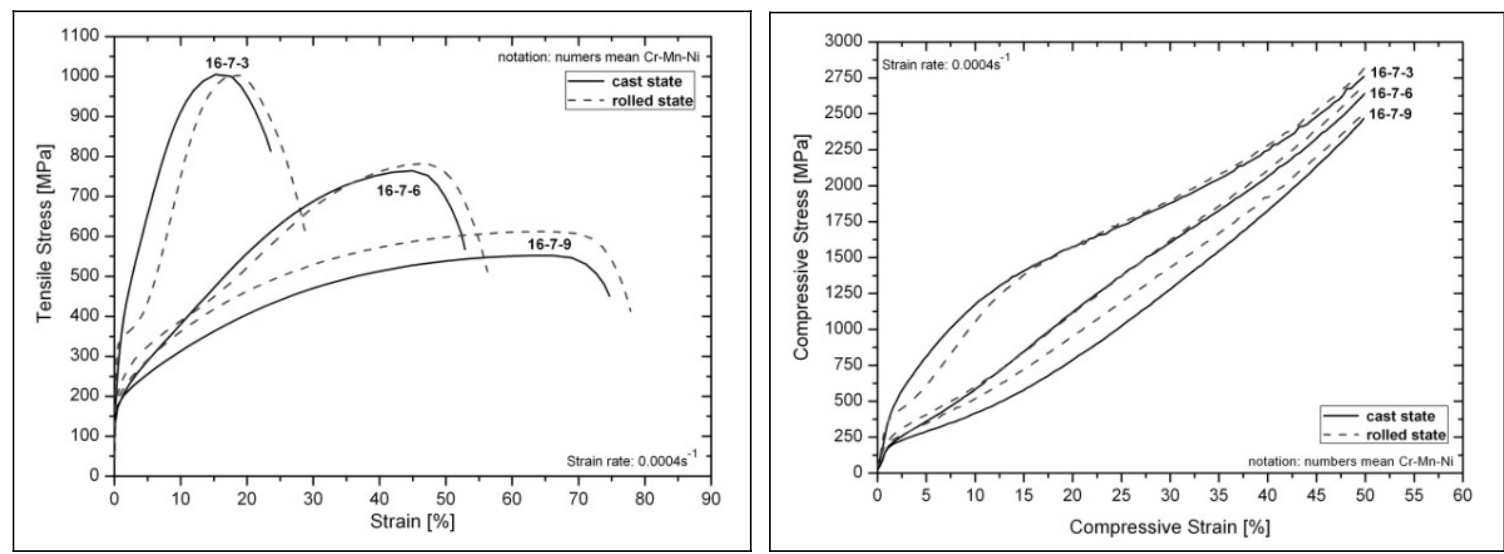

Fig. 1 and 2: Tensile stress-strain curves and compressive stress-strain curves of the investigated steels

Fig. 1 and 2 show a reduction of the strength and the work hardening of the investigated steels with an increasing content of nickel as well as in tensile and compression tests. The strain values increase with a rising nickel content, as shown in Fig. 1. As a consequence of the higher stability of the austenite with higher nickel contents, the strain induced phase fraction of $\alpha^{\prime}$ martensite reaches lower values. This influence of the element nickel on the phase fraction of $\alpha^{\prime}$ martensite is shown in the following chapter. Regarding the curves in Fig. 1, the different alloys show different work hardening mechanisms. Especially in the rolled states, this differentiation is well observable. Alloy 16-7-3 and 16-7-6 show in their stress strain curves two inflexion points, but the alloy 167-9 shows none. Therefore, a strain induced formation of $\alpha^{\prime}$ martensite appears within the alloy 16-7-3 and 16-76, taking place until fracture of the material [4]. Additionally, in the alloy 16-7-9 other work hardening mechanism appears. These mechanisms are the strain induced formation of twins and stacking faults, respectively [7]. Stress strain curves of metastable austenitic Cr-Ni steels show no inflexion points if the 
maximal amount of strain induced formed $\alpha^{\prime}$ martensite is less than $20 \%$ [8]. Regarding the phase fraction measurements of $\alpha^{\prime}$ martensite in the following chapter it is obvious that this research result is also evident for $\mathrm{Cr}-\mathrm{Mn}-\mathrm{Ni}$ steels. It is to notice that alloy 16-7-3 shows only in the rolled state two inflexion points. The reason for this behaviour is a preparatory stress induced formation of $\alpha^{\prime}$ martensite, as shown in a following chapter. This characteristic was observed as well as for tensile and compression loads, as shown in Fig. 1 and 2. Especially the compression tests confirm the tensile test behaviour. The difference between the cast and the rolled state, regarding the mechanical properties, is not significant, as shown in a following chapter.

\section{Martensite phase fraction after maximal loading}

Fig. 3 and 4 shows the ferromagnetic phase fraction which were measured with the magnetic balance. This ferromagnetic phase fraction is equal to the phase fraction of $\alpha^{\prime}$ martensite, except the alloy 16-7-3. In the original state of this alloy the ferromagnetic phase fraction include $\alpha^{\prime}$ martensite and approximately $15 \%$ of ferrite. This fraction of ferrite was measured with the quantitative microstructure analysis at the optical microscope.
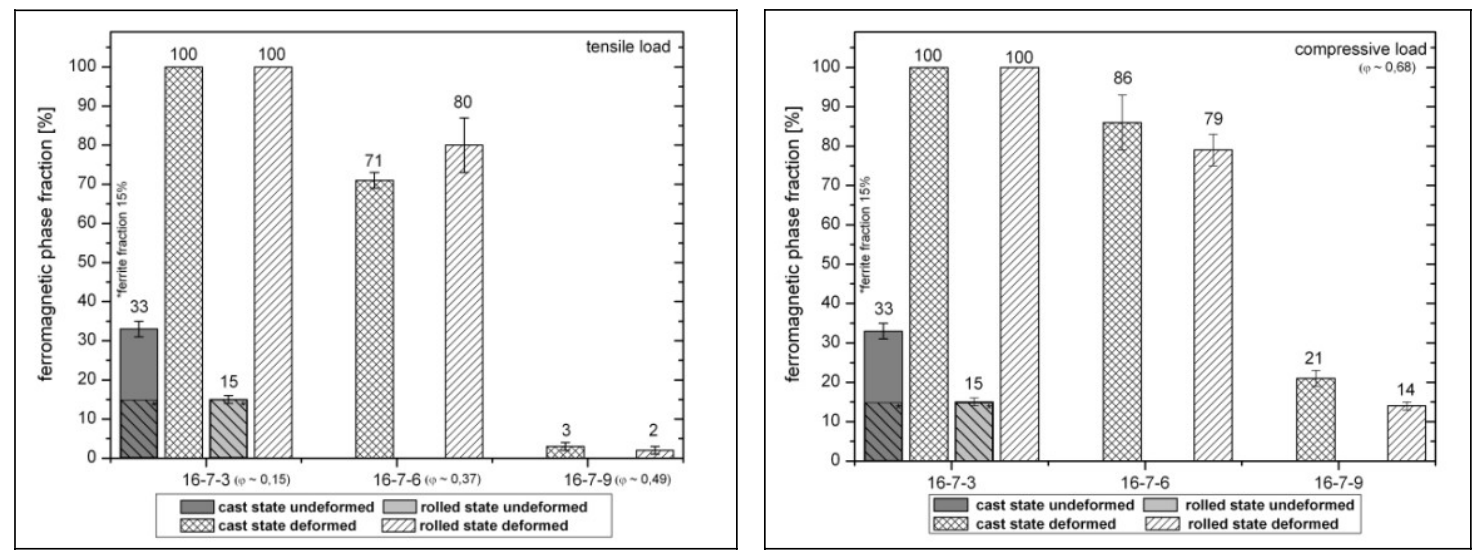

Fig. 3 and 4: Ferromagnetic phase fractions for tensile and compressive loading

The comparison between Fig. 3 and 4 shows that after compression loads a higher measured phase fraction of $\alpha^{\prime}$ martensite occurs than after tensile loads. The reason for this measurement result is the higher deformation degree. In the tensile test the maximal deformation degree $\varphi_{\max }$ is approximately 0.49 , corresponding to uniform elongation value. In the compression test this parameter is 0.68 . Additionally, stress triaxiality occurs in the compression tests. Hence, more shear systems will be activated and so more strain induced $\alpha^{\prime}$ martensite is formed. The decrease of the $\alpha^{\prime}$ martensite is caused to an increasing content of nickel as well as in the tensile and compression tests. Only the compression test shows a significant difference between the cast and the rolled state of alloy 16-7-9. The higher phase fraction of $\alpha^{\prime}$ martensite in the cast state is related to chemical inhomogeneities caused by the dendritic solidification. The non-significant results show that there is no general influence of the material state on the formed $\alpha^{\prime}$ martensite content.

At a constant temperature and loading the strain induced $\alpha^{\prime}$ martensite formation depends on the chemical composition of the steel. Regarding the present research results the $\alpha^{\prime}$ martensite formation is a process which is defined by the local and not by the global chemical composition.

Using EBSD the fcc and bcc phases within the microstructure could be identified. Due to the resolution and the constrained statistics obtained from the partially coarse grained cast states quantitative analysis was not possible. Within the deformed samples the quality of the Kikuchi lines was too bad to achieve reasonable results. Principally it is not possible to identify the nature of the defects, which distort the lattice. Therefore it is not possible to decide whether stacking faults or even $\varepsilon$ martensite forms within the microstructure. So it is an open discussion if the high elongation values of alloy 16-7-9 are caused by the formation of $\varepsilon$ martensite, stacking faults or shear bands. 


\section{Mechanical properties}

Fig. 5 and 6 show the strengths of the investigated alloys for the tensile and compression tests, respectively. According to the DIN 50106 the compression test was stopped at a common compression of $50 \%$.
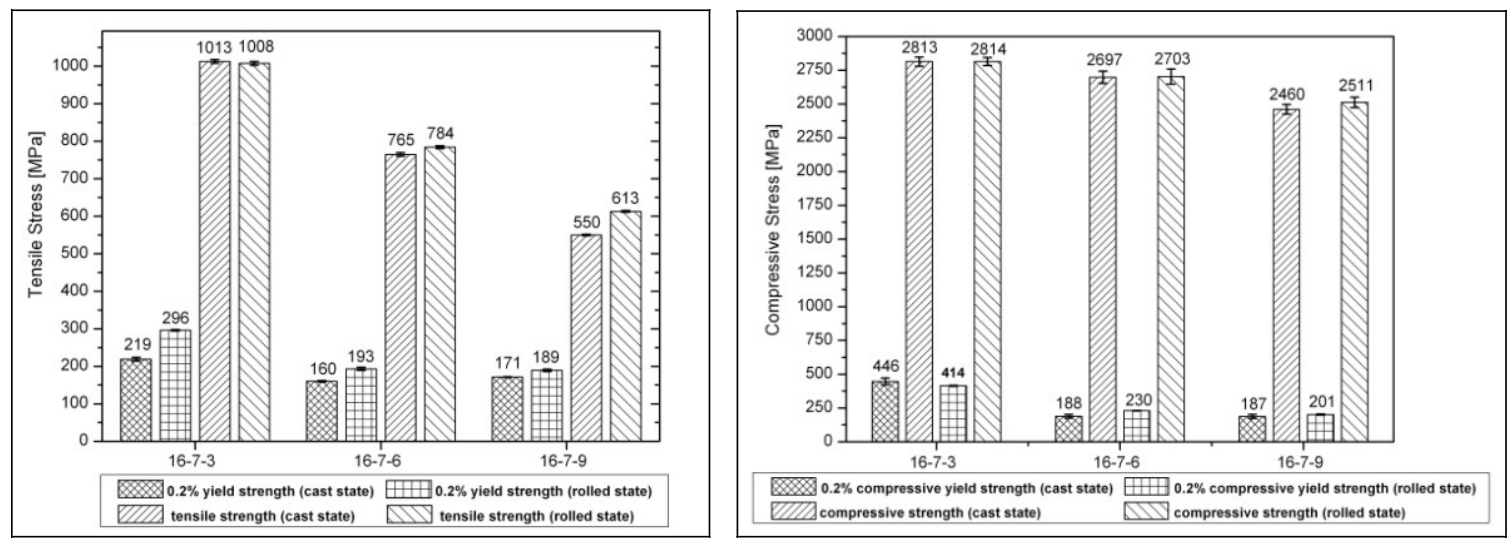

Fig. 5 and 6: Strengths of the investigated steels (tensile test/compression test)

The $0.2 \%$ yield and the $0.2 \%$ compression yield stress of the alloys are higher in the rolled than in the cast state. According to the common level of knowledge this is expected. Typically for the cast state is a coarse grained dendritic microstructure. The grain size in the cast state is with approximately $1000 \mu \mathrm{m}$ much higher than in the rolled state with $20-40 \mu \mathrm{m}$. With an increasing content of nickel the $0.2 \%$ yield stress and the $0.2 \%$ compression yield stress decrease and remain constant, respectively. The alloy 16-7-3 shows an austeniticferritic-martensitic and an austenitic-ferritic microstructure, respectively. Therefore the high $0.2 \%$ yield stress and the $0.2 \%$ compression yield stress are expected. With an increasing content of nickel the original state of the alloys become more stable, the austenitic phase fraction increase and the strength decreases. This is also valid for the cast state, except alloy 16-7-3. Caused by a stress induced formation of $\alpha^{\prime}$ martensite, this alloy must be discussed separately. At the tensile test this phenomena is registered as an apparent decrease of the $0.2 \%$ yield stress $[5,9]$. Therefore the $0.2 \%$ yield strength in the cast state is much lower than in the other alloys. During compression loads the stress induced formation of $\alpha^{\prime}$ martensite is the reason for an increasing of the $0.2 \%$ compression yield strength, as shown in Fig. 6. The influence of the increasing nickel content on the transition elastic-plastic is equal for compression and tension. Fig. 5 shows that the tensile strength of the alloy 16-7-3 is the same in both states. The other alloys show a significant higher tensile strength in the rolled state. Fig. 6 shows that the compressive strengths are the same in both states. With an increasing content of nickel the tensile and the compressive strength are decreasing.

Fig. 7 shows the elongation properties measured in the tensile test.

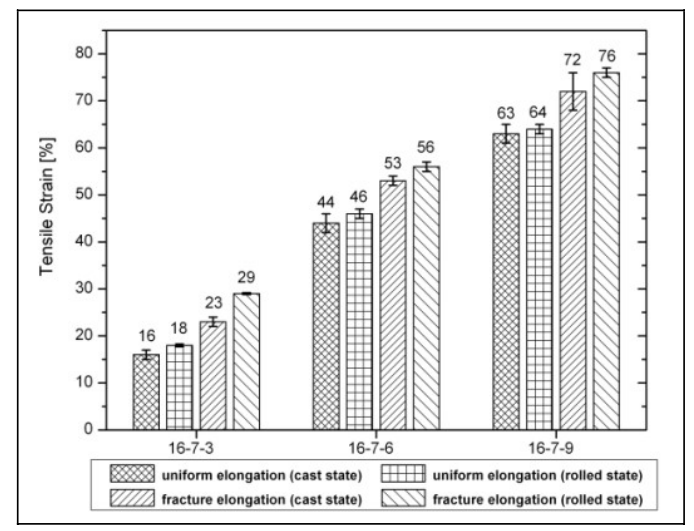

Fig. 7: elongations of the investigated steels (tensile test)

Fig. 7 shows, except the fracture elongation of alloy 16-7-3, no significant difference in the elongation properties between the cast and the rolled state. This difference in the necking behaviour is caused by the large grains in the cast state.

In summary, it can be concluded that the mechanical properties, except the change from the elastic to the plastic material behaviour, are all out of one universal set. The elongation and the strength properties show no 
significant differences between the cast and the rolled state. This surprising finding can be explained by the fact that during the strain induced formation of $\alpha^{\prime}$ martensite, twins and stacking faults a lot of interfaces are generated. During that, the influence of the large grains in the cast state (app. $1000 \mu \mathrm{m}$ ) disappears. The generated interfaces are the dominating factor. So the influence of the grain size on the mechanical properties of the original state can be disregarded. But one important fact must be noticed. Caused by segregations, which are typical for cast states, the stability and the stacking fault energy of the austenite are influenced by the local chemical composition. Alloy 16-7-3 shows this influence of the local chemical composition. The cast state of this alloy shows a stress induced formation of martensite, which does not appear in the rolled state.

According to the mechanical properties (Fig. 5-7) it can be concluded that higher strain induced contents of $\alpha^{\prime}$ martensite cause higher strengths. Thereby the reachable elongations are decreasing. Following, the high strains in alloy 16-7-9 are caused by other effects than a strain induced formation of $\alpha^{\prime}$ martensite [7].

\section{Stress induced formation of $\alpha^{\prime}$ martensite}

Fig. 8 shows the result of stopped tensile tests of the alloy 16-7-3.

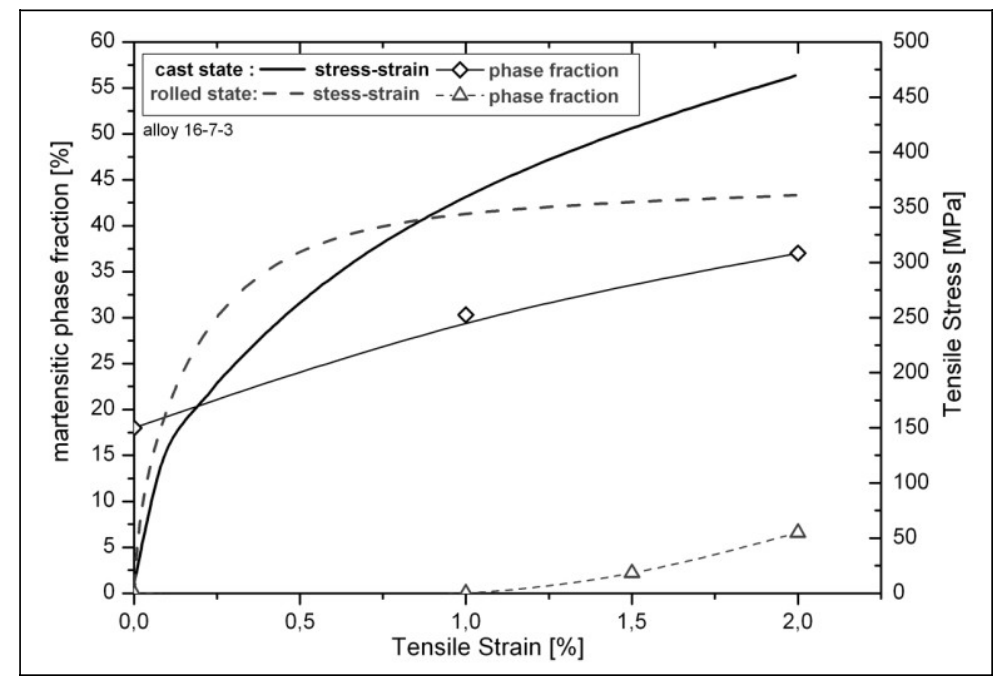

Fig. 8: Martensitic phase fraction and stress-strain curves for alloy 16-7-3 (stopped at 2\% elongation)

Fig. 8 shows, according to the explanations in the previous sections, a stress induced formation of $\alpha^{\prime}$ martensite in alloy 16-7-3. Clearly recognisable is an early change of the slope of the stress strain curve in the cast state. Therefore the $0.2 \%$ yield stress seems to be decreasing. This behaviour can be registered according to the behaviour of some $\mathrm{Cr}-\mathrm{Ni}$ or $\mathrm{Mn}-\mathrm{Ni}$ steels [5,9]. The dilatation of the specimen, caused by the martensite formation, generates an additionally elongation. So the slope of the stress strain curve decreases in the early stages of the tensile test (till approx. $0.8 \%$ ). Following, the calculated elastic module and the $0.2 \%$ yield stress decrease, respectively. At stresses over approx. $350 \mathrm{MPa}$ the strengthening of the formed martensite is dominant and so the work hardening increases (cf. Fig 1). Caused by this early formation of $\alpha^{\prime}$ martensite the different work hardening behaviour of both states of alloy 16-7-3 is explainable.

\section{Isothermal formation of $\alpha^{\prime}$ martensite}

So far, in all shown research results the formation of $\alpha^{\prime}$ martensite was induced by external stresses. Additionally, the formation of $\alpha^{\prime}$ martensite can be isothermal as well. If this formation of martensite takes place the shape of the stress strain curves would be changed. The isothermal formation of $\alpha^{\prime}$ martensite was recognized for alloy 16-7-6 at room temperature. At this temperature this process is so slow, that after 40 days, after the measured ferromagnetic phase fraction (cf. Fig. 3), $1 \%$ of isothermal martensite was formed. Therefore it can be assumed that the tensile and compression tests at room temperature were not influenced by this phenomenon.

Isothermal tests with low temperature dilatometry result in the according isothermal time temperature transformation diagram, as shown in Fig. 9. 


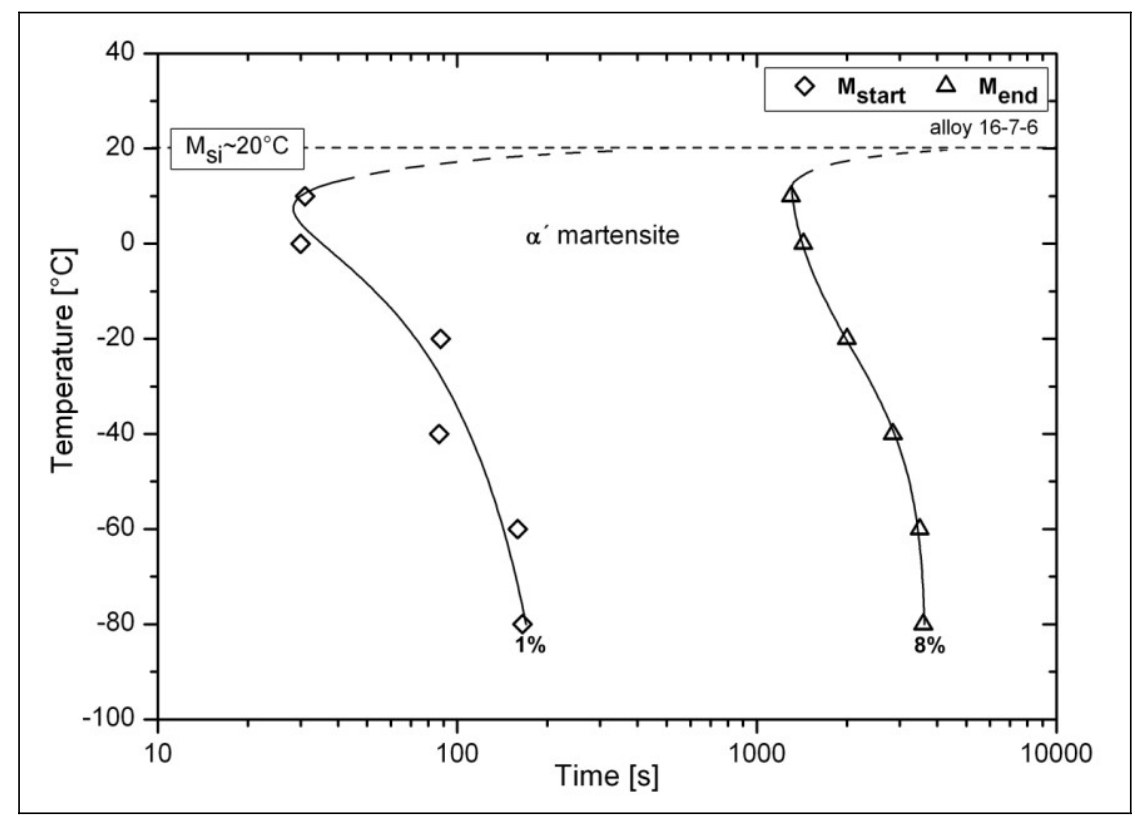

Fig. 9: Isothermal time temperature transformation diagram for alloy 16-7-6

Fig. 9 shows the isothermal transformation behaviour of the alloy 16-7-6. The isothermal formation of $\alpha^{\prime}$ martensite takes place in a temperature range of $0-10^{\circ} \mathrm{C}$ after a time of 40 seconds. At lower temperatures the martensite formation occurs after $100 \mathrm{~s}$. The earliest moment of a finished isothermal transformation was reached after 30 minutes. At temperatures lower than $-20^{\circ} \mathrm{C}$ the formation finished after app. 50-70 minutes. The formed $\alpha^{\prime}$ martensite phase fraction reaches a value of approximately $8 \%$. Metastable austenitic $\mathrm{Cr}-\mathrm{Ni}$ steels with low stacking fault energy of the austenite show an isothermal formation of martensite [10-12]. Based on the investigations, it can be concluded that also metastable austenitic $\mathrm{Cr}-\mathrm{Mn}-\mathrm{Ni}$ steels show this phenomenon. It can be assumed that the isothermal formation of martensite is initiated by a thermal activated formation of dislocations [11].

Fig. 10 shows the microstructure at room temperature of the alloy 16-7-6 before any deformation. Recognisable are the needle like martensite crystals in the austenite.
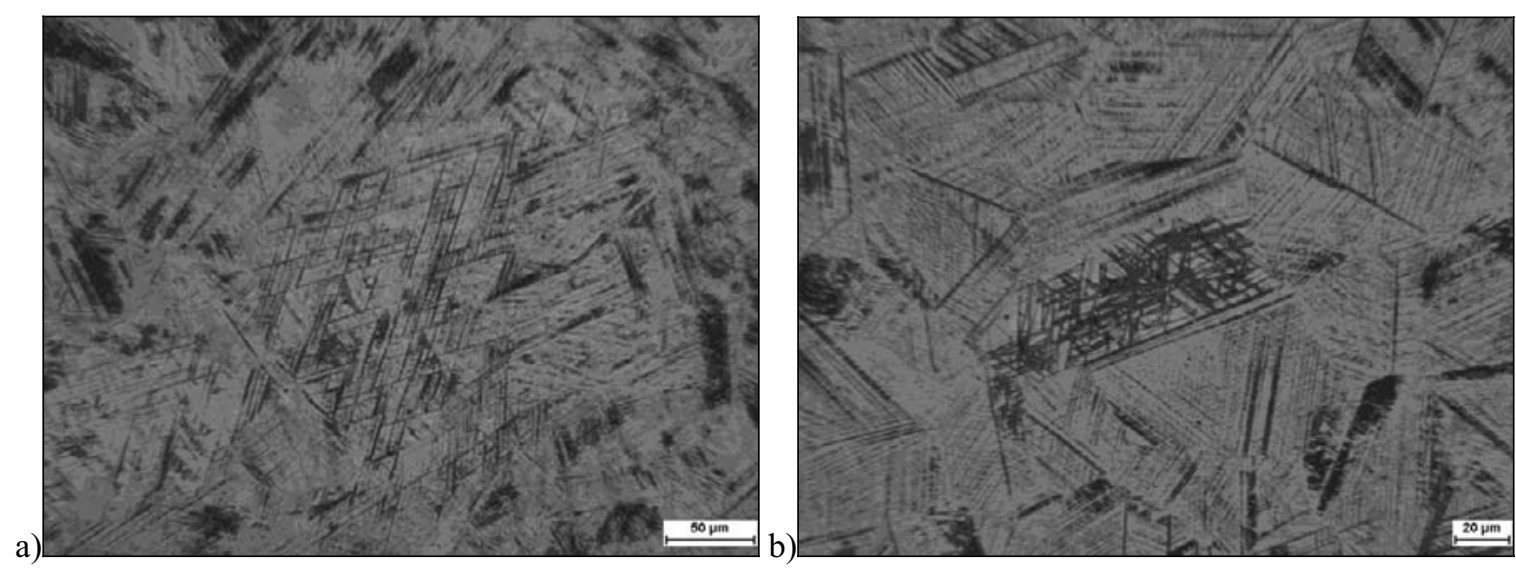

Fig. 10: isothermal martensite in alloy 16-7-6 (a- cast state, b- rolled state; optical microscopy)

It can be steady that the formed martensite content in the alloy 16-7-6 is defined besides external loadings by the temperature and the time.

\section{Summary}

The investigations showed that rolled and cast $\mathrm{Cr}-\mathrm{Mn}-\mathrm{Ni}$ steels with an austenitic, austenitic-ferritc and austenitc-ferritc-martensitc microstructure show the TRIP effect. Between the two investigated states, cast and rolled, there were no significant differences in the mechanicals properties. This is valid for tensile as well as compressive loading. With an increasing content of nickel the strain induced phase fraction of $\alpha^{\prime}$ martensite is decreasing. Consequently the maximal strengths are decreasing and the strains increases. Hence, the high strains 
are the result of other microstructural effects than the strain induced formation of $\alpha^{\prime}$ martensite. Under compressive loads a higher phase fraction of $\alpha^{\prime}$ martensite was encountered. This was the result of higher deformation degrees and the stress triaxiality. A significant influence of the cast or rolled state on the $\alpha^{\prime}$ martensite formation was not registered. One of the investigated alloys (16-7-3) shows in the cast state a stress induced formation of martensite. Thus, the $0.2 \%$ yield stress seems to decrease in the tensile test and in the compression test the $0.2 \%$ compression yield stress increases. The alloy 16-7-6 shows in both states, the cast and the rolled, an isothermal formation of martensite. An according isothermal time temperature transformation diagram was shown.

\section{Acknowledgements}

The authors would like to thank all of the involved staff in the collaborative research centre 799 and the German Scientific Council (DFG) for financial support of these investigations.

\section{References}

[1] Weiß, A., Gutte, H., Radke, M., Scheller, P.R.: patent specification WO002008009722A1

[2] Tamura, I.: Metal Science, Vol.16, Mai 1982, 245

[3] Weiß, A., Gutte, H., Scheller, P.R.: Steel grips, (2003) 4, 283-288

[4] Weiß, A. Gutte, H., Scheller, P.R: Steel research int. 77 (2006) 9-10, 727-732

[5] Fahr, D.: Metallurg. Trans. 2, 7, (1971) 1883-1892

[6] Kaufman, L., Breedis, J. F.: Metallurg. Trans. 2(1971) 9, 2359-2371

[7] Weiß, A., Jahn, A., et al., unpublished research results, manuscript in preparation

[8] Weiß, A.; Gutte, H. et al: Proceedings of the 5th European Stainless Steel Science and Market Congress, Sevillia, 2005

[9] Schumann, H.: „Dilatationseffekte bei martensitischen Phasenumwandlungen in metastabilen austenitischen CrNi-Stählen“, wissenschaftliche Berichte des Zentralinstituts für Festkörperphysik Dresden, Nr. 20, 1979

[10] Eckstein, H.-J.; Weiß, A., Neue Hütte, No. 8 (1987), 290

[11] Nishiyama, Z.: „Martensitic Transformation“, Academic Press, New York, 1978

[12] Borgenstam, A., Hillert, M., Acta materialica 48 (2000) 2777-2785 